\title{
Lumpers and Splitters: Ongoing Issues in the Classification of Large Vessel Vasculitis
}

Large vessel vasculitis (LVV) is defined as inflammation that affects the aorta and its major branches. Takayasu arteritis (TAK) and giant cell arteritis (GCA) are the 2 main forms of $\mathrm{LVV}^{1}$. Historically, GCA is considered a disease of the elderly that targets the extracranial arteries (e.g., carotid and temporal arteries). In contrast, TAK typically affects younger patients and targets the aorta and its primary branches (e.g., subclavian and renal arteries). However, increasing evidence, primarily based on radiographic studies, demonstrates that vasculitic involvement of the aorta and primary branches can occur in GCA in addition to the more widely recognized cranial features of the disease ${ }^{2}$. Current estimates about the prevalence of involvement of the aorta and primary branches in GCA vary widely across different cohorts, but large vessel pathology is apparent by angiography in about $20 \%-30 \%$ of patients with $\mathrm{GCA}^{3,4}$. There are no existing guidelines regarding screening for large artery involvement in GCA, so the incidence of large vessel disease in GCA may be underestimated. An older necropsy study of 4 patients with GCA and known temporal arteritis, in which there was no clinical suspicion for vasculitis in the aorta and branch vessels, demonstrated widespread vasculitic lesions throughout the large arteries in every patient ${ }^{5}$. Cumulative incidence rates of large vessel involvement in GCA have increased dramatically over the last 2 decades in parallel with increased awareness about this feature of $\mathrm{GCA}^{6}$.

Recognition of involvement of vessels beyond the extracranial arteries as a feature of GCA has created new challenges in the disease classification of LVV. The 1990 American College of Rheumatology (ACR) Classification Criteria for GCA were developed in a time when involvement of the aorta and primary branches was not a well-recognized feature of GCA and are focused on the cranial aspects of the disease ${ }^{7}$. In contrast, the 1990 ACR Classification Criteria for TAK focus on clinical features of arterial damage related to the aorta and primary branches (e.g., limb claudication) ${ }^{7}$.

About two-thirds of patients with GCA and large vessel disease have involvement of the aorta or primary branches in the absence of cranial features of disease (e.g., headache, jaw claudication, ocular disease, positive temporal artery biopsy $)^{8,9}$. Differentiating the subset of patients with GCA who do not have cranial features of disease from patients with TAK is difficult. Age is incorporated into existing criteria for both GCA and TAK; consequently, age is often arbitrarily applied as the primary determinant of disease classification in a patient with large vessel vasculitis. Involvement of the aorta and primary branches with disease onset at $<40$ years is classified as TAK, and large vessel involvement with disease onset at $>50$ years is often classified as GCA.

Based upon observed similarities between TAK and GCA, there are suggestions that these 2 conditions may exist on a spectrum within the same disease ${ }^{10}$. The histopathology of vasculitic lesions is indistinguishable between the 2 diseases ${ }^{5}$. Common genetic variants (e.g., FCGR2A/FCGR3A) have been identified ${ }^{11}$. There is overlap in the signs and symptoms at presentation ${ }^{10}$. An ongoing therapeutic trial in large vessel vasculitis is studying treatment effect in a combined cohort of patients with TAK or GCA (NCT00556439). Our group recently reported on the distribution of arterial lesions in patients with TAK or GCA and found striking similarities between the 2 diseases $^{8}$. Lesions tended to be contiguous in the aorta and symmetric in branch vessels in both diseases. The distribution of affected vessels was similar with few exceptions. There was notably increased axillary artery involvement in GCA, and a high prevalence of left subclavian artery involvement was seen in TAK. Using latent class analysis, a statistical technique to identify potentially unobservable subgroups within a population, there was little differentiation between the 2 diseases on the basis of patterns of arterial involvement. We suggested that TAK and GCA might exist on the same spectrum of disease with subtle skewing of disease phenotypes influenced by immunosenescence.

In the current issue of The Journal, Furuta, et al report upon findings in a cohort of patients with $\mathrm{LVV}^{12}$. Unlike our previous work, which focused only upon angiographic data, the authors expand the scope of comparison between TAK and GCA to include clinical and laboratory data. Only

See TAK vs GCA: Different diseases or a single entity?, page 300

Personal non-commercial use only. The Journal of Rheumatology Copyright (c) 2015. All rights reserved. 
patients with GCA and known involvement of the aorta and primary branches were included in this study. These patients with GCA were found to have more frequent headaches and higher levels of acute inflammatory markers at the time of diagnosis than patients with TAK. Distribution of vascular lesions was similar between TAK and GCA; however, the authors report differences in the character of the vascular lesions. Long-tapered stenotic lesions were more frequent in the subclavian/axillary arteries in GCA compared to TAK. The natural history of the diseases was also different, with more relapse noted in the GCA group. When all these variables were factored into latent class analysis models, 2 separate groups emerged that aligned with the traditional diagnoses of TAK and GCA. The authors conclude that although there are angiographic similarities between the diseases, broader differences in terms of clinical symptoms, inflammatory markers, clinical outcomes, and radiologic findings suggest that TAK and GCA are indeed separate diseases.

As more reports emerge that focus upon the subset of patients with GCA and involvement of the aorta or primary branches, it is important to evaluate how GCA and large vessel involvement are defined in each study. Different definitions of GCA may influence the proportion of patients with and without cranial symptoms of disease within a cohort, and there may be important differences between these subgroups. Patients diagnosed with large vessel GCA in absence of cranial symptoms tend to be younger, have more relapses, require more intensive therapy, and have higher mortality rates compared to patients with GCA who have cranial features of disease ${ }^{9,13}$. In the study by Furuta, et al ${ }^{12}$, GCA was defined by the presence of arterial lesions in the aorta and/or primary branch vessels attributed to vasculitis and either age $>50$ years at disease onset or fulfillment of the 1990 ACR Classification Criteria for GCA. Given this definition, the majority of the 22 patients with GCA in their study had large vessel disease in absence of cranial symptoms. For example, only 6 out of 22 patients with GCA reported headache, 1 patient reported jaw claudication, and no patient reported loss of vision. Differences in the definition used to classify GCA can strongly influence the composition of the study population and may affect both the nature of the study results and the generalizability of findings across different cohorts of patients with GCA.

Criteria used to define and to screen for arterial involvement can also significantly influence the study population. The prevalence of large vessel disease in patients with GCA can vary widely depending upon the imaging modality used to screen for disease (angiography $20-30 \%{ }^{3,4}$; positron emission tomography $30-80 \% 14,15$; ultrasound $30 \% 16,17,18$ ). In the study by Furuta, et al, an arterial lesion was defined by either increased wall thickness or stenosis/occlusion or aneurysm attributed to vasculitis, detected by computed tomography or magnetic resonance imaging angiography. Inclusion of wall thickness abnormal- ities in the definition of arterial lesions may also influence the prevalence of arterial involvement. Wall thickness abnormalities can be a nonspecific finding seen with increased prevalence in aging populations and/or related to atherosclerosis ${ }^{19}$. In the study by Furuta, et al, 11 of 22 patients with GCA (50\%) included in the cohort were diagnosed with involvement of the aorta and/or primary branches on the basis of wall thickness abnormalities alone in the absence of other changes on angiography. In our group's previously reported study of arterial disease patterns in TAK and GCA, wall thickness abnormalities were not included in the definition of arterial disease ${ }^{8}$. Thus, comparing results across these studies is challenging.

There are a few potential limitations from the study by Furuta, et al to consider. As the authors note, this is a retrospective single-center study that may be subject to recall, referral, and misclassification bias. Without standardized prospective data collection, differential misclassification bias with respect to exposure status may confound the clinical differences noted between TAK and GCA. In particular, cranial features of disease may be preferentially recorded in patients with GCA because they are historically not considered to be features of TAK. Systematically collected data in prospective cohorts will help to clarify potential clinical similarities and differences between TAK and GCA; however, whether TAK and GCA are the same or different diseases will likely be answered through studies of the underlying biologic basis of disease rather than by comparisons across clinical phenotypes.

If the purpose of classification criteria is to standardize disease definitions to ensure that the same disease entity is consistently studied ${ }^{20}$, then the current challenges in defining subsets of LVV highlight the need for new classification criteria in LVV. Updated classification criteria for vasculitis are currently being developed using prospectively collected data from a large cohort of patients with many different types of vasculitis ${ }^{21}$. These data should help further clarify the phenotypic similarities and differences between TAK and GCA and should be used to explore the possibility of redefining subsets of disease within LVV.

PETER C. GRAYSON, MD, MSc,

US National Institutes of Health,

National Institute of Arthritis and Musculoskeletal and Skin Diseases (NIAMS),

Vasculitis Translational Research Program, Bethesda, Maryland, USA.

Address correspondence to Dr. P.C. Grayson, National Institutes of Health, 10 Center Drive, Building 10, 6N Rm 216G, Bethesda, Maryland 20892, USA. E-mail: peter.grayson@nih.gov

Supported through the Intramural Research Program at NIAMS.

\section{REFERENCES}

1. Jennette JC, Falk RJ, Bacon PA, Basu N, Cid MC, Ferrario F, et al. 2012 revised International Chapel Hill Consensus Conference Nomenclature of Vasculitides. Arthritis Rheum 2013;65:1-11.

Personal non-commercial use only. The Journal of Rheumatology Copyright $@$ 2015 . All rights reserved. 
2. Cid MC, Prieto-González S, Arguis P, Espígol-Frigolé G, Butjosa M, Hernández-Rodríguez J, et al. The spectrum of vascular involvement in giant-cell arteritis: clinical consequences of detrimental vascular remodelling at different sites. APMIS Suppl 2009; 127:10-20.

3. Nuenninghoff DM, Hunder GG, Christianson TJ, McClelland RL, Matteson EL. Incidence and predictors of large-artery complication (aortic aneurysm, aortic dissection, and/or large-artery stenosis) in patients with giant cell arteritis: a population-based study over 50 years. Arthritis Rheum 2003;48:3522-31.

4. García-Martínez A, Hernández-Rodríguez J, Arguis P, Paredes P, Segarra M, Lozano E, et al. Development of aortic aneurysm/dilatation during the followup of patients with giant cell arteritis: a cross-sectional screening of fifty-four prospectively followed patients. Arthritis Rheum 2008;59:422-30.

5. Ostberg G. Morphological changes in the large arteries in polymyalgia arteritica. Acta Med Scand Suppl 1972;533:135-59.

6. Kermani TA, Warrington KJ, Crowson CS, Ytterberg SR, Hunder GG, Gabriel SE, et al. Large-vessel involvement in giant cell arteritis: a population-based cohort study of the incidence-trends and prognosis. Ann Rheum Dis 2013;72:1989-94.

7. Arend WP, Michel BA, Bloch DA, Hunder GG, Calabrese LH, Edworthy SM, et al. The American College of Rheumatology 1990 criteria for the classification of Takayasu arteritis. Arthritis Rheum 1990;33:1129-34.

8. Grayson PC, Maksimowicz-McKinnon K, Clark TM, Tomasson G, Cuthbertson D, Carette S, et al. Distribution of arterial lesions in Takayasu's arteritis and giant cell arteritis. Ann Rheum Dis 2012;71:1329-34.

9. Muratore F, Kermani TA, Crowson CS, Green AB, Salvarani C, Matteson EL, et al. Large-vessel giant cell arteritis: a cohort study. Rheumatology 2014 Sep 5 (E-pub ahead of print).

10. Maksimowicz-McKinnon K, Clark TM, Hoffman GS. Takayasu arteritis and giant cell arteritis: a spectrum within the same disease? Medicine 2009;88:221-6.

11. Saruhan-Direskeneli G, Hughes T, Aksu K, Keser G, Coit P, Aydin SZ, et al. Identification of multiple genetic susceptibility loci in Takayasu arteritis. Am J Hum Genet 2013;93:298-305.

12. Furuta S, Cousins C, Chaudhry A, Jayne D. Clinical features and radiological findings in large vessel vasculitis: Are Takayasu arteritis and giant cell arteritis 2 different diseases or a single entity? J Rheumatol 2015;42:300-8.

13. Nuenninghoff DM, Hunder GG, Christianson TJ, McClelland RL, Matteson EL. Mortality of large-artery complication (aortic aneurysm, aortic dissection, and/or large-artery stenosis) in patients with giant cell arteritis: a population-based study over 50 years. Arthritis Rheum 2003;48:3532-7.

14. Brodmann M, Lipp RW, Passath A, Seinost G, Pabst E, Pilger E. The role of 2-18F-fluoro-2-deoxy-D-glucose positron emission tomography in the diagnosis of giant cell arteritis of the temporal arteries. Rheumatology 2004;43:241-2.

15. Blockmans D, de Ceuninck L, Vanderschueren S, Knockaert D, Mortelmans L, Bobbaers H. Repetitive 18F-fluorodeoxyglucose positron emission tomography in giant cell arteritis: a prospective study of 35 patients. Arthritis Rheum 2006;55:131-7.

16. Schmidt WA, Seifert A, Gromnica-Ihle E, Krause A, Natusch A Ultrasound of proximal upper extremity arteries to increase the diagnostic yield in large-vessel giant cell arteritis. Rheumatology 2008;47:96-101.

17. Aschwanden M, Kesten F, Stern M, Thalhammer C, Walker UA, Tyndall A, et al. Vascular involvement in patients with giant cell arteritis determined by duplex sonography of $2 \times 11$ arterial regions. Ann Rheum Dis 2010;69:1356-9.

18. Ghinoi A, Pipitone N, Nicolini A, Boiardi L, Silingardi M, Germanò G, et al. Large-vessel involvement in recent-onset giant cell arteritis: a case-control colour-Doppler sonography study. Rheumatology 2012;51:730-4.

19. Rosero EB, Peshock RM, Khera A, Clagett P, Lo H, Timaran CH. Sex, race, and age distributions of mean aortic wall thickness in a multiethnic population-based sample. J Vasc Surg 2011;53:950-7.

20. Singh JA, Solomon DH, Dougados M, Felson D, Hawker G, Katz $\mathrm{P}$, et al. Development of classification and response criteria for rheumatic diseases. Arthritis Rheum 2006;55:348-52.

21. Craven A, Robson J, Ponte C, Grayson PC, Suppiah R, Judge A, et al. ACR/EULAR-endorsed study to develop diagnostic and classification criteria for vasculitis (DCVAS). Clin Exp Nephrol 2013;17:619-21.

J Rheumatol 2015;42:149-51; doi:10.3899/jrheum.141376 